\title{
SENTINEL-1 PROCESSING AND ANALYSIS TO ESTIMATE GROUND DISPLACEMENT AND IDENTIFY ACTIVATION FAULTS, CASE STUDY OF THE 2017 Mw 7.3 EARTHQUAKE, NEAR THE IRAQ-IRAN BORDER
}

\author{
${ }^{1}$ Ammar Abd Jasim and ${ }^{2}$ Mustafa Ali Hassan \\ ${ }^{1}$ Center of Remote Sensing, Ministry of Science and Technology, Baghdad, Iraq \\ ${ }^{2}$ Department of Geology, University of Baghdad, Baghdad, Iraq \\ *E-mail:ammory.1977@yahoo.com \\ Received: 19 December 2019; accepted: 29 February 2020
}

\begin{abstract}
Earthquakes are significant natural geohazards that threaten life and property. Iraq lies in a seismically active region, and most earthquakes result from the collision of the EurasianArabian plates. On Nov. 12, 2017, an earthquake with $7.3 \mathrm{MW}$ shook a large area of the Zagros Belt at the Iran-Iraq border. This work aims to use the InSAR technique for emphasis on the processing and analysis of Sentinel-1 data pre and post-earthquake supported by field, geological and tectonic information to map the ground deformation and fault activity caused by the Nov.12 earthquake. The case study involves a region located at the Iraq-Iran political boundaries. The results reveal that InSAR is a powerful tool to detect ground displacement and allow positioning faults. The interferogram results show that deformation extends to an area $\sim 6300 \mathrm{~km}^{2}$ and $7000 \mathrm{~km}^{2}$, with a maximum line-of-sight horizontal displacement $\sim 87 \mathrm{~cm}$ and $\sim 55 \mathrm{~cm}$, vertical displacement $\sim 121 \mathrm{~cm}$ uplifting and $\sim 59 \mathrm{~cm}$ subsidence for ascending and descending data respectively, While pre-earthquake results show clearly neither displacement nor deformation took place. According to InSAR analysis, displacement direction, fault position detection, aftershock distribution, and the general geometric fault context, the blind back-thrust fault $S W$-dipping steeply occurred on the Zagros Front Fault was interpreted, in addition to new minor faults ruptured on the surface and displacement on old faults were detected. Many faults derived from the geological map coincide with the results of interferometric phase maps. Most recently discovered faults appear to be related to the Nov.12 earthquake.
\end{abstract}

Keywords: Earthquakes; Faults; Displacement; InSAR technique; Sentinel-1 


\section{INTRODUCTION}

Earthquakes are responsible for the great loss of life and destruction of property. Most earthquakes take place along regions of Earth's crust deformation and most of that deformation results from plate tectonic forces or other reasons such as volcanic/hydrothermal, gravity, and anthropic processes (Vilardo et al., 2009). The deformation kind that occurs during the earthquake usually exists along with rocks fracture zones that generate faults. The seismic activity in Iraq is long and well documented, with 79 events documented as having significant and/or minor impacts on society (Alsinawi \& Ghalib, 1975). Earthquakes in Iraq are more known after 1900 within the boundary of the Iraq earthquake map in with most of the shocks in the depth of the Earth's crust. (Ghalib \& Alsinawi, 1974). As a consequence of the compressing of the plates, earthquakes were observed inside the plate again and again. Therefore, a general increase can be distinguished in earthquakes activity in Iraq from west to east and from south to north (Alridha \& Mohammed, 2015).

Until the late $20^{\text {th }}$ century, measurement of Earth's deformation was time-consuming (Pritchard, 2006) and many accurate field measurements could not be made, particularly in complex topography and geology areas such as the current study area with the absence of modern GPS stations to overcome many of these limitations, the InSAR (Interferometric Synthetic Aperture Radar) technique utilizing radar image can be used to assess changes in earth's surface elevation, measuring the deformation and displacement and recent activity of faults caused by the earthquakes with high precision. InSAR is a well-established and authoritative technique for studying displacement of earth's surface and can be used to recover historical deformation, determine small size anomalies and discover deformation limits with a measurement accuracy of a centimeter to the millimeter. (Qu et al., 2019). InSAR features such as high spatial accuracy, broad spatial coverage, and no fieldwork needed, make it as one of the top ways to measure surface displacement. (Hu et al., 2010). Since the European Space Agency (ESA) launch of the ERS-1 satellite in 1991, ERS-2 in 1995 the topic of interferometric processing of signals from the SAR, has a lot of attention.

On November 12, 2017, a strong 7.3 MW earthquake occurred in the region in Iraq and Iran border (Chenet al., 2018), it is of about $220 \mathrm{~km}$ northeast of Baghdad, Iraq at 21:18 by Iraq Standard Time (18:18 UTC) https://earthquake.usgs.gov. It was the largest since the 11 January $1967 \mathrm{Mw} 6.1$ (about $104 \mathrm{~km}$ southeast of Nov. 12 earthquake). The seismic event was felt by people in large areas that covered Iraq, Syria, Iran and, eastern Turkey (Zare et al., 2017). The earthquake killed more than 140 victims and 800 injuries, immense building damages and large economic losses (Chen et al., 2018). This work aims to use the InSAR 
technique and emphasis on the processing, analysis, and application of Sentinel-1 data supported by field, geological and tectonic information to map deformation of the ground surface and fault activity result by the Nov. 12, 2017 earthquake.

\section{STUDY AREA AND DATA SET}

\section{The Study Area Location}

The study area is located in the northeast of Iraq in the Diyala province, north of the city of Khanaqin on the political border between Iraq and Iran, which is considered one of the most active cities of earthquakes in Iraq (Abdulnaby et al., 2016); it covers more than $10000 \mathrm{~km}^{2}$ (Fig. 1). It is located between longitudes $45^{\circ} 15^{\prime} 00^{\prime \prime}-46^{\circ} 15^{\prime} 00^{\prime \prime}$ and latitudes $34^{\circ} 15^{\prime} 00^{\prime \prime}-$ $35^{\circ} 15^{\prime} 00$.

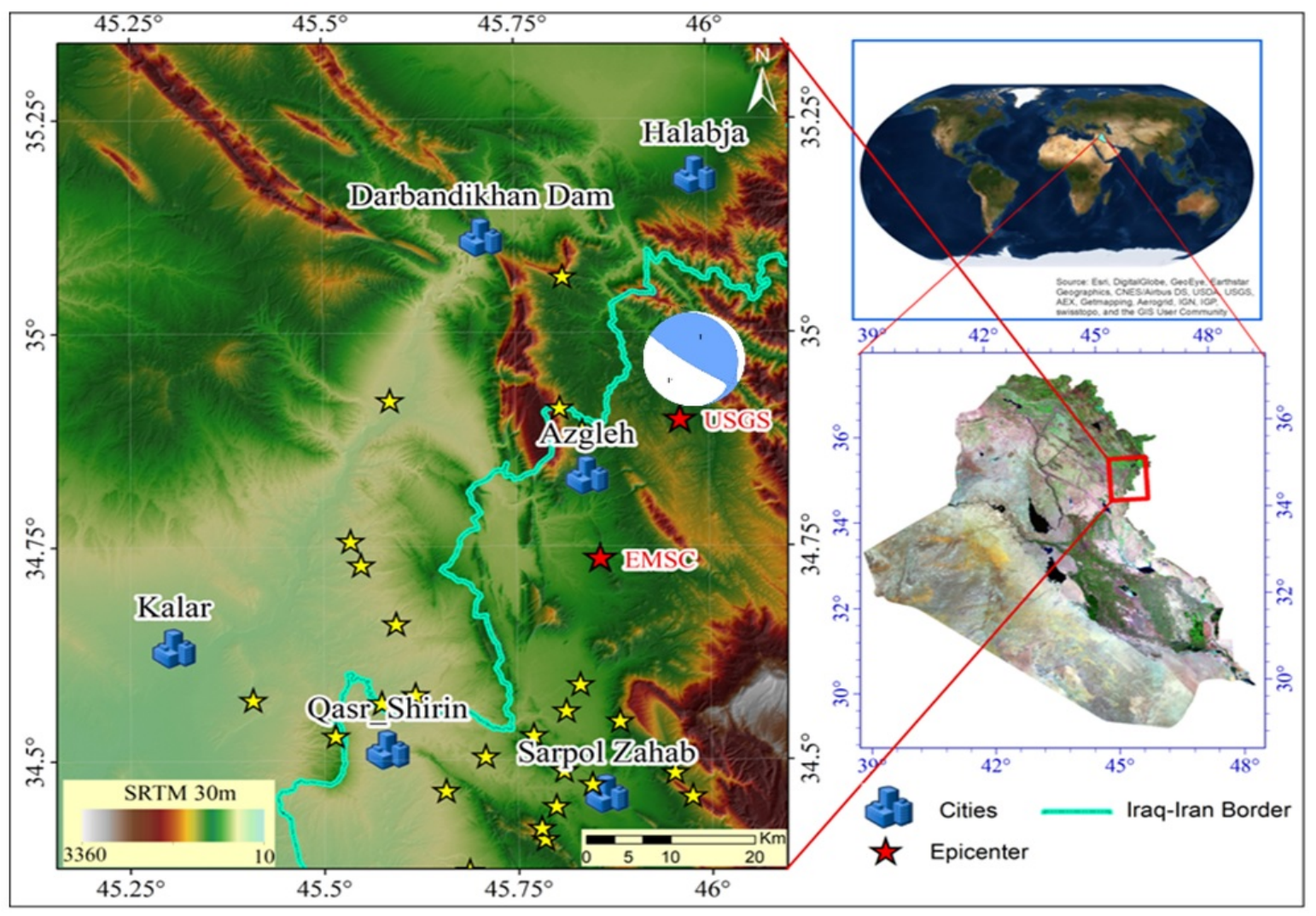

Fig. 1. SRTM DEM 30m (Farr et al., 2007) superimposed on a hillshaded shows the location of the study area at the Iraq-Iran border. The epicenter determined from two seismological agencies (USGS and EMSC) is represented by the red star. The beach balls are the focal mechanism solution for the Nov. 12 earthquake mainshock (USGS, https://earthquake.usgs.gov/). The yellow star marks the earthquake's epicenter based on the European-Mediterranean Seismological Centre archives (http://www.emsccsem.org) during the period of Sentinel-1 acquired (Nov. 7-19, 2017). 


\section{Tectonics and Geological Setting}

The Arabian plate forms one tectonic plate, and It is encompassed on various sides by the boundaries of active plates, as shown by seismic sites. (Adams \& Barazangi, 1984). The plate of the Arabian Peninsula is one of the largest terrestrial blocks that have been grouped and was moved several kilometers as the unit since the late Cretaceous period of relative transition in relation to the African, Somali, Eurasian, Iranian, Anatolian plates (Alsinawi, 2002)

Iraq is considered as a part of the minor earthquake belt in the Alps and Himalayas, it is situated on the northeastern edge of the Arabian plate, and about $95 \%$ of Iraqi lands belong to the northern part of the Arabian platform (Fouad, 2015). Because of this, the earthquakes in Iraq have shown a direct relationship with the general direction of the earthquakes from the Thrust Belt and Bitlis-Zagros fold. (Abdulnaby et al., 2014). The regional tectonics are predominated by the Arabian Plate subduction beneath the plate of Eurasian along with the thrust systems of Zagros and Bitlis in the east, seafloor spreading and rifting in the Gulf of Aden and the Red Sea in the west. Strike-slip faulting takes place along the Dead Sea transform fault systems and the Gulf of Aqabah in the north (Al-Amri et al., 2008). The study area, like other neighboring regions, was affected by the Alpine movement that began in the late Triassic period (Al-Jiboury, 1991). Therefore, Tectonically Iraq is located in a relatively active seismic zone at the northeastern boundaries of the Arabian Plate.

Tectonically, the area of study exists in three tectonic zones, the High Folded and Imbricate zones on the NE part, while the rest belongs to Low Folded Zone (Fouad, 2015). The unstable shelf according to the bipartite classification extended within the following area: Foothill and High Folded zones. The area of study located close and within the collision zone between tectonic plates of the Arabian and Eurasian which belongs to the Zagros collision zone (Sadeghi \& Yassaghi, 2016). Geologically, the study area is built up of sedimentary rocks extending in age from Late Jurassic to recent, with different types of Quaternary sediments and the basin was built-up by a folding sedimentary sequence (Al-Sudani, 2018).

\section{Data Set}

For the analyses of deformation and displacement caused by an earthquake on Nov. 12, 2017, images of Sentinel-1 (S-1) SAR data were utilized. The modern generation SAR mission of the ESA consists of two satellites, Sentinel1-A and Sentinel1-B satellites, which launched on April 3, 2014, and April 25, 2016, respectively (Shirzaei et al., 2017), The C-band SAR new generation mission of the ESA provides significant coverage of $250 \mathrm{Km}$ for swath width, 6 days repeat cycle, dual-polarization mode (VH and VV), and medium spatial accuracy (1020m). S-1 is acquired in the Level-1 Single Look Complex (SLC) data format and in the mode of Interferometric Wide (IW). These features of Sentinell satellite with the availability 
of $~ 5 y$ years of an open-access archive, supply more information about the ground for study the events of deformation and displacement. There are more than 20 pairs of S-1 a dataset cover all/some of the study areas with a temporal baseline from 6 days to 24 days; during the period Oct. 25, 2017, to Nov. 25, 2017, available on ESA website; Sentinel Scientific Data Hub (https://scihub.copernicus.eu/). In this work, three pairs (Table.1) selected, one ascending pair is acquired pre-earthquake, while the last two ascending and descending pairs are acquired before and after the earthquake. The combination of an image acquired before and after the earthquake can be utilized to measure the displacement result from the earthquake on the line of satellite-object (Xia, 2005).

Table 1. Interferometric pairs of Sentinel-1 data, acquisition date and their specifications

\begin{tabular}{|c|c|c|c|c|c|c|c|}
\hline $\begin{array}{l}\text { Earthquake } \\
12 \text { Nov. } 2017\end{array}$ & $\begin{array}{c}\text { Acquisition } \\
\text { Date }\end{array}$ & $\begin{array}{c}\text { Pass } \\
\text { Direction } \\
\text { And Mode }\end{array}$ & Path & $\begin{array}{c}\text { Temporal } \\
\text { baseline } \\
\text { Day }\end{array}$ & $\begin{array}{c}\text { Perpendicul- } \\
\text { ar baseline } \\
\mathrm{B} \perp\end{array}$ & $\begin{array}{c}\text { Mean } \\
\text { Coherence }\end{array}$ & $\begin{array}{c}\text { Incidence } \\
\text { angle }\end{array}$ \\
\hline $\begin{array}{c}\text { Pre- } \\
\text { Earthquake }\end{array}$ & $\begin{array}{l}30 \text { Oct. and } \\
11 \text { Nov. } \\
2017\end{array}$ & $\begin{array}{l}\text { Ascending } \\
\text { IW_SLC }\end{array}$ & 72 & 12 & 40.7 & 0.63 & $36.3-46$ \\
\hline \multirow{2}{*}{$\begin{array}{c}\text { Post- } \\
\text { Earthquake }\end{array}$} & $\begin{array}{l}11 \text { Nov. and } \\
17 \text { Nov. } \\
2017\end{array}$ & $\begin{array}{l}\text { Ascending } \\
\text { IW_SLC }\end{array}$ & 72 & 6 & 62.2 & 0.71 & $36.3-46$ \\
\hline & $\begin{array}{c}12 \text { Nov. and } \\
24 \text { Nov. } \\
2017\end{array}$ & $\begin{array}{c}\text { Descending } \\
\text { IW_SLC }\end{array}$ & 6 & 12 & $45.3 \mathrm{~m}$ & 0.58 & $41.7-46$ \\
\hline
\end{tabular}

\section{METHODOLOGY}

In recent years, InSAR techniques have proven their ability to elicit the information of ground deformation with high accuracy of SAR images. (Curlander \& McDonough, 1991). SAR is a technology in which two or more SAR images for the same region and path obtained in an identical geometrical configuration are combined at two different times to discover a large scale surface change, line-of-sight displacement (LOS) to the satellite. (Nishimura et al., 2008). Minor changes to the ground alter the reflected of radar signals and result in a fringe of rainbow-colored of "interference" (Fig. 2). The methodology of this paper involves three main steps:

\section{Selecting Suitable Insar Images for Interferometry}

Choosing the appropriate SAR images for interferometry is the first step that should be taken for any processing of interferometric. Selecting pairs of images that may have the necessary properties for the interferogram formation is an essential step because the approved standards for the selecting images have a high influence on the goodness of the results of the final image. For deformation, the following recommendations criteria should be followed: 
1- Before download SAR data, make sure that both data sets cover the same slice and track number, both from the same mode and same orbit ascending or descending, in particular in W-E and flight direction. So for interferometry, you cannot combine ascending and descending images, or images from different tracks or different modes (Fig. 3A).

2- Select the smallest temporal baselines acquisitions that can be obtained to reduce temporal decorrelation. The longer the temporal baselines between the images the higher is temporal decorrelation. With the Sentinel-1 radar (C-band), can't expect to make any useful InSAR measurements unless you use very short time intervals.

3- Local weather has an impact on the values of Coherence (Ferretti et al., 2007). So, most avoid processing SAR images in the climatic of snow, rain, or strong wind. Also, avoid the images obtained on very hot days (Hanssen, 1998). The weather conditions generally result in a loss of phase coherence. In vegetated areas, usually image pairs obtained in the dry season usually show values of higher coherence than those obtained in the rainy season.

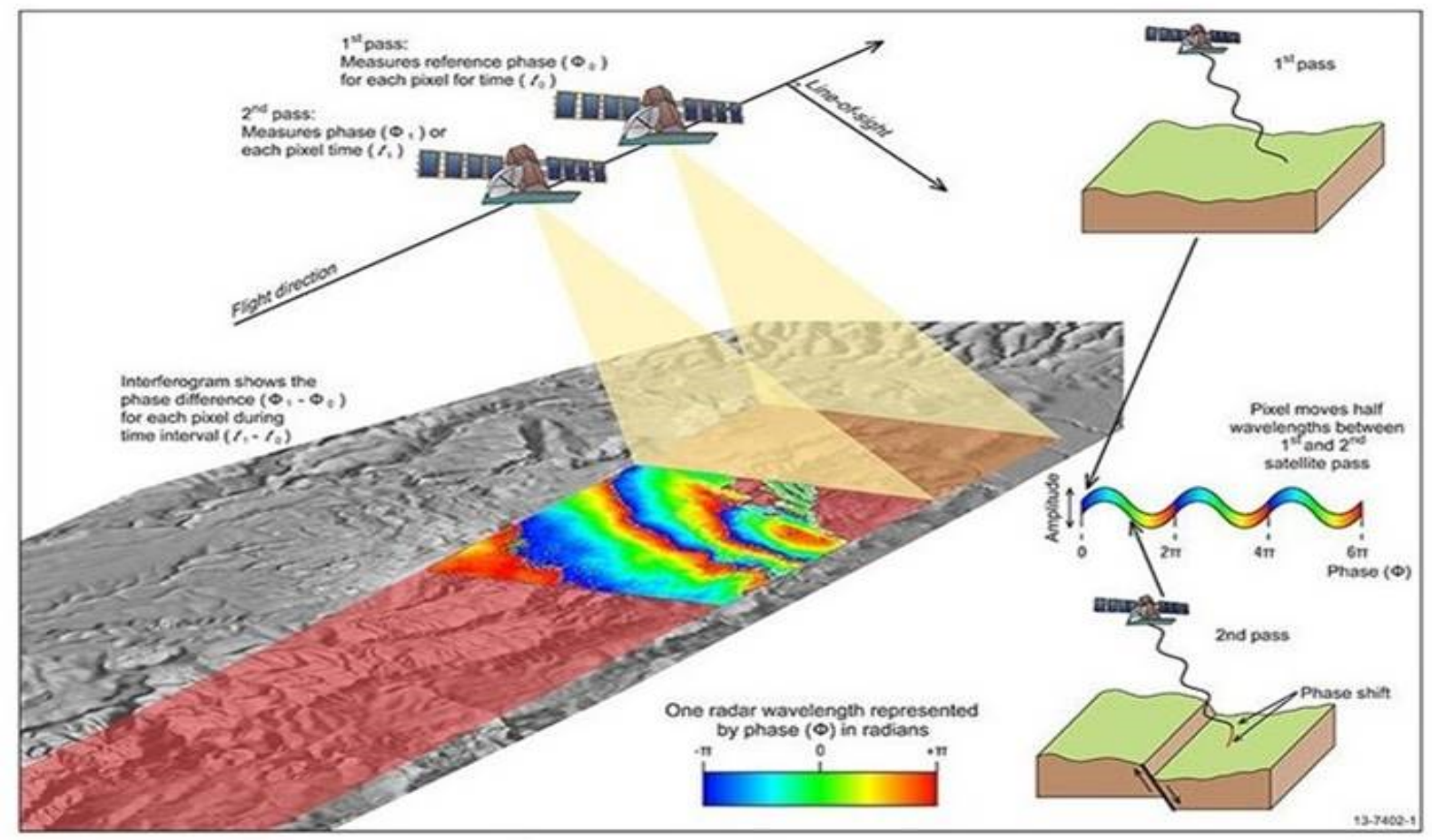

Fig. 2. InSAR: Illustration how InSAR works if the distance between the satellites and ground increases between two acquisition dates due to surface displacement, the phase measured at each date is also changing 

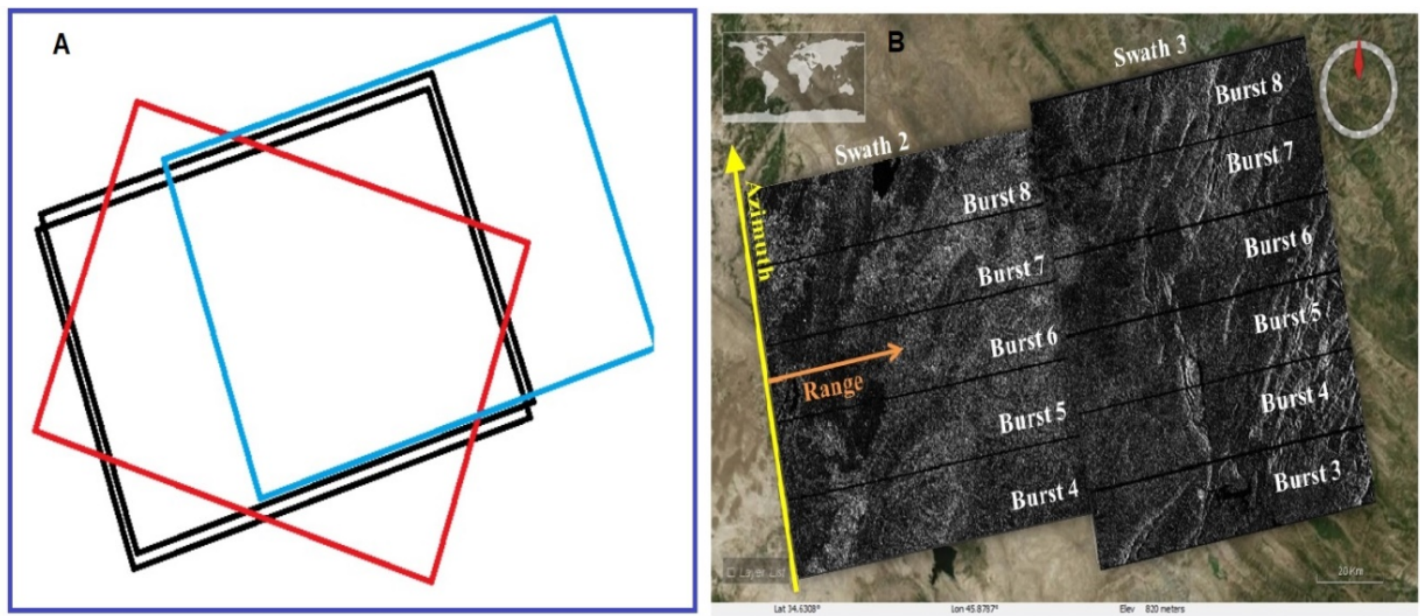

Fig. 3. A. Sentinel-1 footprints, for example, you can use the two black images, but not black with red or blue images. $B$. Two sub-swaths of $S-1$ for ascending pass cover the study area, swath 2 with 5 bursts and swath 3 with 6 bursts

\section{Insar Processing}

The interferometric wide swath (IW) mode of the S-1 radar sensor has 3 sub-swaths through the Terrain Observation Progressive Scans (TOPS) imaging technique. Every sub-swath includes a series of bursts, one burst has consisted of the order of azimuth time. Each burst will be treated as a discrete SLC image. The study area covers with a different number of bursts for ascending and descending pass (Fig. 3B). So, the first step after a download suitable Sentinel-1 image is to subset the study area to reduce data size and processing time.

There are five different sources that contribute to the pixel difference in the overall interference phase as equation 1 (Oveisgharan \& Zebker, 2006; Veci, 2015):

$$
\phi_{\text {InSAR }}=\phi_{\text {flat }}+\phi_{\text {topo }}+\phi_{\text {defo }}+\phi_{a t m}+\phi_{\text {noi }}
$$

Where, $\phi_{\text {InSAR }}$ the phase interferometric,

$\phi_{\text {flat }}$ the phase of flat earth; this contribution is due to the curvature of the Earth;

$\phi_{\text {topo }}$ the phase of topographic,

$\phi_{\text {defo }}$ the phase of deformation,

$\phi_{\mathrm{atm}}$ the phase of atmospheric delay,

$\phi_{n o i}$ the phase of noise resulting from temporal decorrelation, the difference of look angles, the volume of scattering and other noise.

The interferometry process tries to eliminate sources of other errors and get the interested contributor of error only, in our case is typically the deformation phase. The phase of flat earth $\phi_{f l a t}$ and phase of noise $\phi_{n o i}$ can be treated by utilizing the corrected information of orbit, apply the method of interferogram filtering and considered as an error source, see equation 2 (Zhang et al., 2012). 


$$
\phi_{\text {flat }}=\frac{4 \pi x_{0}}{\lambda\left(r_{m}-r_{s}\right)} \Delta_{x}
$$

Where, $\mathrm{x}_{0}$ is the shortest distance from ground trace to swath, $\Delta \mathrm{x}$ is the displacement range direction distance from swath, $r_{m}$ the distance of the shortest slant range from the master image, $r_{s}$ is the distance of the shortest slant range from slave image (Huang et al., 2000). Considering the ideal situation where the atmospheric condition $\left(\phi_{\text {atm }}\right)$ does not change between the two acquisition dates ( 6 and 12 days only, with no rain or different climate conditions), and the topography phase $\phi_{\text {topo }}$ will be corrected using an external DEM (SRTM with $30 \mathrm{~m}$ resolution) and orbital data, then the difference in phase between the master and slave images is related to the deformation (Mousavi Zahra, 2010), the equation (1) reduces to equation 3:

$$
\phi_{\text {InSAR }}=\phi_{\text {Deformation phase }}
$$

Production of interferometric SAR images, data sets involve multiple processes starting with download suitable Sentinel-1 data which must be complex SAR image type, then SAR images must be registered slave to the master image, information of Interferometric phase pixel-bypixel will be extracted, then analyzed the coherence, Phase is unwrapped (removes modulo$2 \pi$ ambiguity), the phase is interpolated and converted into displacement, finally Interferometric image is geocoded (Fig. 4).

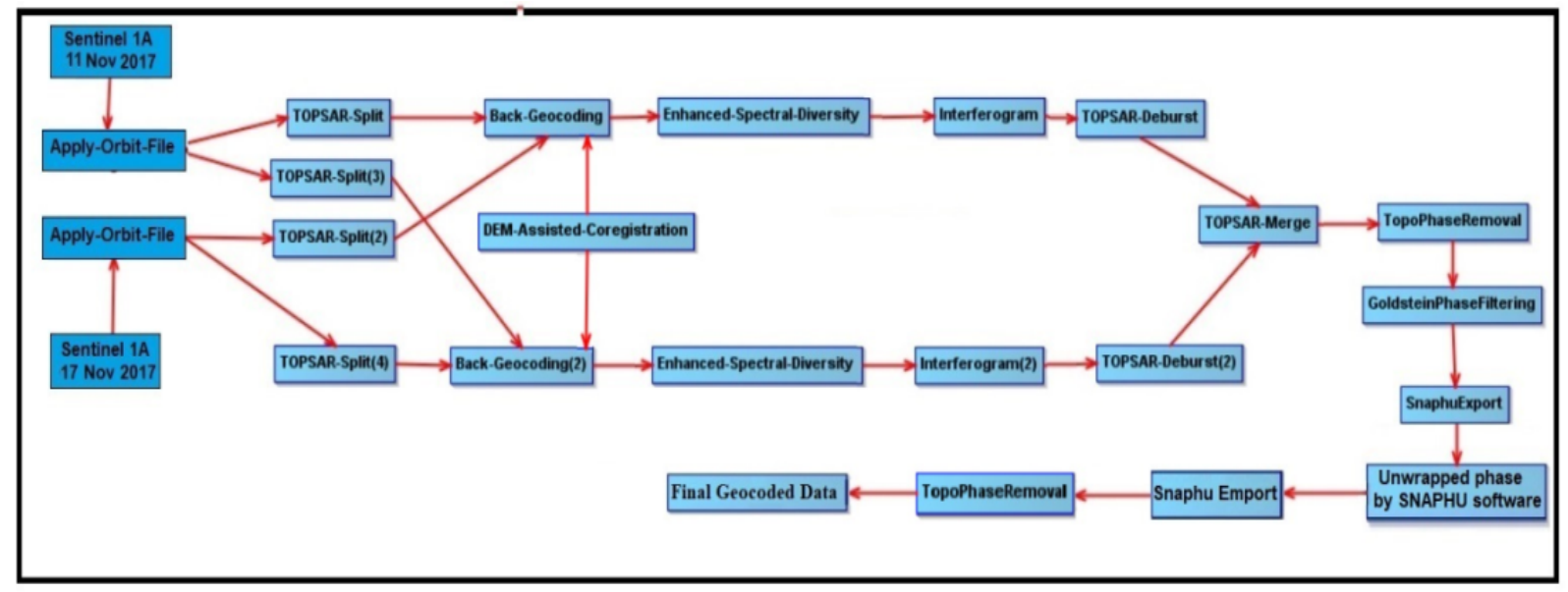

Fig. 4. Diagram of the steps performed for S1A by using SNAP \& SNAPHU softwares

Pre-processing of interferometric phase, the images (two or more) should be coregistered, the first image must be selected as the master which is used as a geometric reference and the other images are the slaves. To improve coregistration accuracy, applying a range of different methods (Sakar et al., 2015). Therefore, the algorithm of standard matching utilizing an external digital elevation model (SRTM version3 30m), geometric alignment depends on 
accurate orbital (Sansosti et al., 2006) which are available three weeks after the acquisition for S-1(Sentinels, 2013), deramping of Level-1 Single Look Complex (SLC) data prior to interpolation (Miranda, 2014), in addition to employing the Enhanced Spectral Diversity (ESD) approach to overall errors correction of misregistration (Prats-Iraola et al., 2012).

After co-registration, the interferogram for two SAR images is generated to calculated Complex interferograms, any complex pixel in master image multiplying by the conjugate of the corresponding complex pixel of slave image (Colesanti \& Wasowski, 2006). The variation of interferometric phase $\Delta \phi$ is proportionate to $\Delta \mathrm{R}$ divided by the transmitted wavelength $\lambda$, As in equation 4 (Veci, 2015):

$$
\Delta \phi=\phi_{1}-\phi_{2}=\frac{4 \pi \Delta R}{\lambda}
$$

Two separate processes after interferograms needed to be applied in order to generate a broad-area from the Interferometric Wide (IW) mode (Agency, 2013), Debursting and Merging. Deburst is processing concatenates the individual bursts from one sub-swath together into a single deburst sub-swath. Merging, mosaicked the sub-swaths into a single wide-swath (Fig. 5).

The interferogram results will be high noisy and the patterns of fringe are difficult to understand. Hence, better exploitation of the topographic phase removed by subtracts topographic contribution phase from the interferogram by used external DEM, 1 arc-second DEM of NASA's Shuttle Radar Topography Mission SRTM used. The topographic phase removed from the interferograms must reduce the noise (Zebker \& Lu, 1998). The interferograms then will be smoothed with the power of spectrum filter called Goldstein filtering proposed by (Goldstein \& Werner, 1998) which is a processing technique that greatly reduces the residues in the later on phase unwrapping and enhances its accuracy. Goldstein filtering applies to increase the ability to unwrapping the properly phase, increasing the signal to noise ratio, and enhance the appearance of the interferogram fringes.

Usually, the original SAR images appear speckled with inherent speckle noise. Therefore, many images are combined inconsistently as if they are compatible with different looks from the same scene to reduce the inherent speckled appearance. This process is usually known as multilooking processing. Multilook averaging is the preferred method (Olmsted, 1993) used for SAR image formation in order to reduce the speckle noise (Moreira, 1991), and raise the ratio of signal-to-noise for interferograms images (Lu \& Dzurisin, 2014). The phase interferometry is significantly improved, and the pattern of fringe is now clearly visible after apply filtering. But the phase is ambiguous and only known module $2 \pi$ (Chelbi et al., 2011), to get a continued relief profile through the entire scene, the phase of interferometric 
should be unwrapped. The unwrapping of phase (removes modulo $-2 \pi$ ambiguity) is the processing of adding the correct integer multiple of $2 \pi$ to the fringes of interferometric to be the able to join the phase of interferometric to the displacement. Unwrapped carried out utilizing the SNAPHU software (C. W. Chen, 2001).

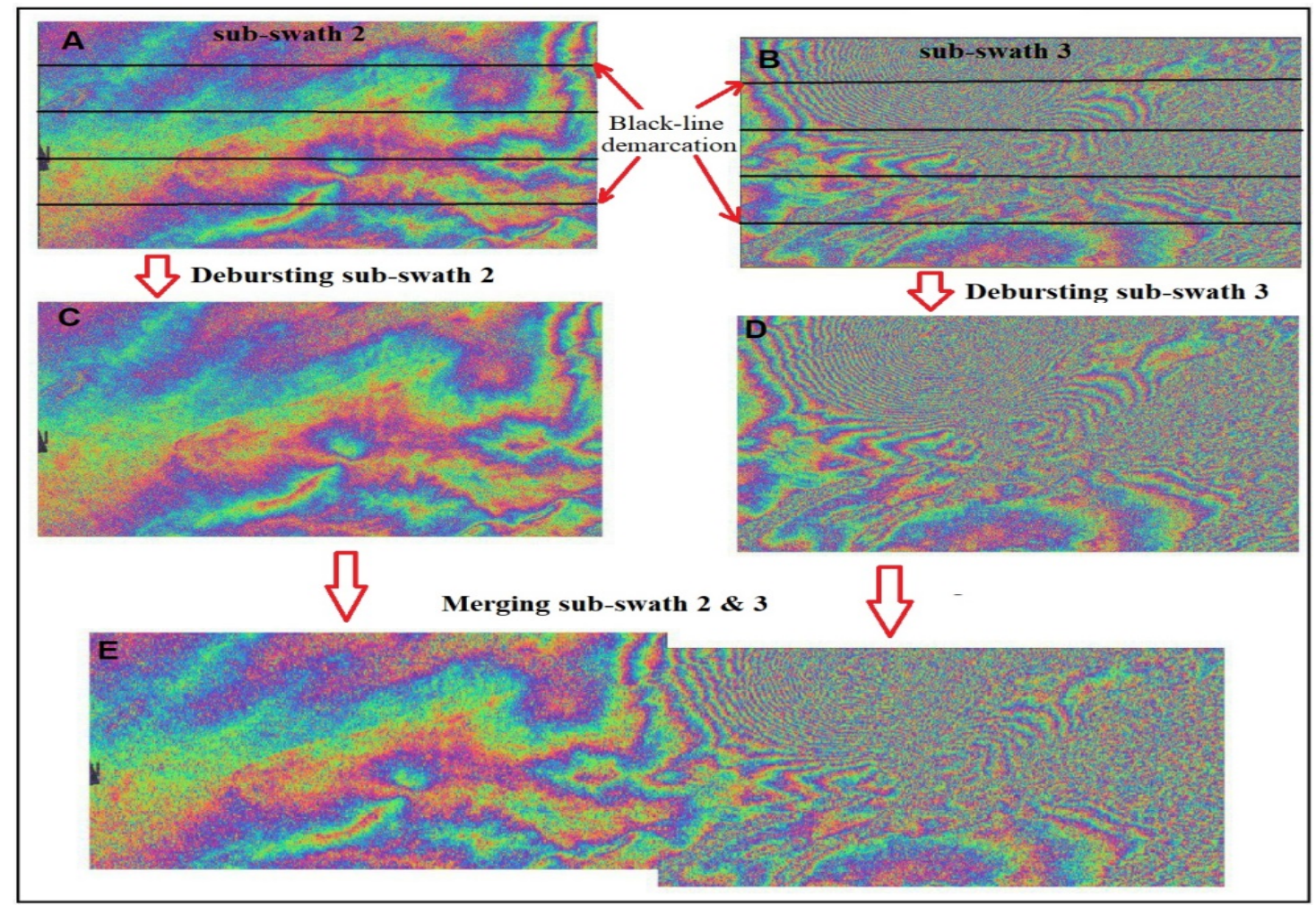

Fig. 5. The arrangement of bursts in an IW mode with the black-line demarcation between sub-sequent bursts (A) Sub-swath2 (B) sub-swath3. S-1 Deburst to produce a single deburst sub-swath (C) Debursting sub-swath2 (D) Debursting sub-swath3, (E) Mosaic or merging for a full S-1 Interferometric Wide Swath consisting of two subswaths with 5 bursts each

\section{Insar to Identify and Monitor Faults}

In the area of complex tectonic settings, the information about the active structures interaction is necessary to comprehend the continental deformation mechanisms and to assess the location of the potential fault of an earthquake. (H. Wanga et al., 2017). Faulting displacement results in property damages and requires further investigation. The detection of faults could be accomplished by several methods such as aerial and satellite imagery interpretation. (Al-Azzawi \& Hamdoon, 2008). Ground surface surveys, which are the primary methods of identifying and monitoring surface faults fracture, drilling of wells can be providing important evidence about position and direction of the deeper faults, in addition to various ground-based geophysical surveys that can be used to fault detection. 
Remote sensing techniques can be providing a strong tool for detecting the location and geometries of the subsurface fault (Barnhart et al., 2018; Elliott et al., 2016; Jouanne et al., 2011). InSAR techniques have been demonstrated to be an active method of deformations mapping along and/or across the traces of faults and sometimes can be indicated to subsurface location faults (blind faults). Deformation gradient discontinuity through the lines of fault provides an opportunity to faults mapping across InSAR maps since the two sides of the faults usually moved past each other and to have different rates of deformation. (Qu et al., 2015). Many phase discontinuities areas have been distinguished and clearly featured in most InSAR maps especially the phase maps, with avoid phase data discontinuity result from decoherence phenomena result from many reasons such as low signal of SNR radar, layover, and shadows distortion result from the topography effect, etc. InSAR measurements allow positioning both already recognized traces of faults as well as the new fractures nucleation that was not previously detected by other Earth / Space technologies.

\section{RESULTS AND DISCUSSIONS}

\section{Interferometric Fringes Interpretation}

The differential interferogram images produced by the SNAP software (European Space Agency, 2019) (Fig.6) help to understand how the earthquakes affected land in the area, making it possible to analyses, how the ground has shifted as a result of the seismic activity If the interference is processed by two radar scenes data obtained consecutively before and after the earthquake, then this interference contains the information about terrain and deformation results from the earthquake.

Three pairs interferograms showed in Figures (6 a, b, and c) after flatting and are derived from the data of ascending pair Oct. 30/ Nov. 11 (per-earthquake event) and from the ascending and descending data pairs Nov.11/ Nov.17 and Nov. 7-19 (post-earthquake event) respectively. The fringe patterns associated with the earthquake, where each color cycle demonstrates the phase variation of $[-2 \pi]$, in the images of ascending and descending orbitals look similar, with both patterns indicate the dominant vertical deformation (uplift). The deformation extends to an area of approximately $6300 \mathrm{~km}^{2}$ (90 km long and $70 \mathrm{~km}$ width) for ascending orbit and $7000 \mathrm{~km}^{2}$ (100 km long and $80 \mathrm{~km}$ width) for descending orbit (Fig.6 b\&c respectively). For InSAR data acquired over the region on Oct. 30 and Nov. 11 (Fig. 6a), preearthquake by one day; there is neither fringes clear nor deformation took place before the Nov. 12 earthquake. The inhomogeneous results of the differentiation processes prove there is a change in the topography in the area after the earthquake. 
The InSAR results of ground deformation will be represented by the change of fringe colors; the gentle deformation causes the gentle change of fringe color while the steep deformation of the ground does the steeped change of fringe color (Fig. 6e). The distance between each fringe represents ground movement, the closer together the fringes indicated to greater the strain experienced by the ground during the earthquake, especially the area closed to faults.

The results of InSAR are mostly shown as a picture with colored fringes and it is similar to the rainbow-colored fringes formed on a soap bubble, for example. There is a deformation in the area where the color turns from blue to green to red to purple (the will display sequence depends on a used computer software). Here, it must be noticed that the fact rainbow-colors of fringes repeat cyclically, turning from blue to green to red to purple and turning back to blue. In addition to that, rainbow-colors of each fringe, turning from positive to negative values, these values can be displayed in radian ( $\pi$ to $-\pi$ or 3.14 to -3.14 ) or metric units (equal to the wavelength of the radar satellite, because the $S-1$ has a wavelength $\sim 5.6 \mathrm{~cm}$, the fringe will turn from 2.8 to $-2.8 \mathrm{~cm}$ ). On the phase map, the fringe color turning from positive to negative (blue to purple) reference to uplift direction while fringe color turning from negative to positive (purple to blue) reference to subsidence direction (Fig. 6d).

\section{Vertical and Horizontal Displacement}

The phase of interferometric is ambiguous and known only within $2 \pi$. To make the phase of interferometric join the topographic height, the phase should first be unwrapped (Fig.7 a\&b). The altitude of ambiguity is defined as the difference of altitude which generates a change in the interference phase from $2 \pi$ after flattening of the interferogram phase.

This ambiguity will be fixed after phase unwrapping by merging the difference of phase for neighboring pixels. Next to deleting any integer number of altitudes of ambiguity, the difference of phase between two points on the flattened interferogram supply measurement of the true variation of altitude. The homogeneous results for the unwrapping process (Fig.7 a \& b) prove that the integral has no error and no phase jumping. Figs. $7 \mathrm{a}$ and $7 \mathrm{~b}$ indicated that the deformation mainly appears near the city of Azgleh (Iran), this lead to think this city located on the main predicted blind fault (fault that does not reach the surface) caused by the earthquake. After an unwrapped phase by using SNAPHU software, produced displacement in LOS (Line Of Sight) geometry, which represents the horizontal displacement (Fig. $7 \mathrm{c}$ and d), and vertical displacement (Fig. 7 e \& f) using the following equations, (FerrettiA \& GuarnieriA, 2007);

$$
\text { Disp. In LOS }=\frac{(d * \lambda)}{(-4 * \pi)}
$$




$$
\text { Vertical Disp. In LOS }=\frac{(d * \lambda)}{(-4 * \pi * \cos (\operatorname{rad}(\theta))}
$$

Where, $d$ is the phase unwrapping,

$\theta$ the incidence angle of radiation with respect to the reference;

$\lambda$ the wavelength of SAR ( $56 \mathrm{~mm}$ for Sentinel-1).

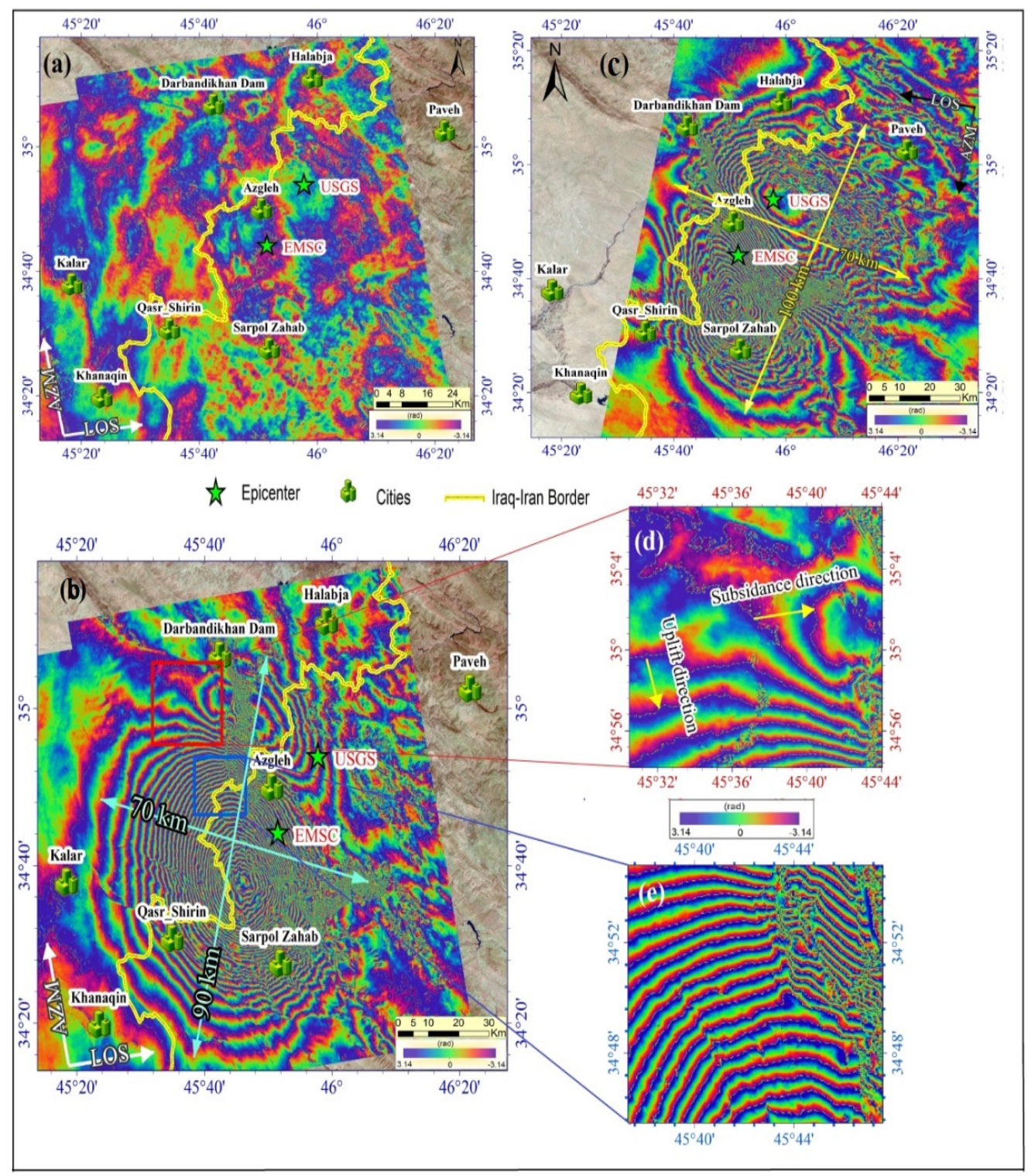

Fig. 6. Interferogram three wrapped InSAR images, (a) InSAR from ascending orbit (Oct. 30 to Nov. 11) pre-earthquake, it is clearly neither displacement nor deformation occurring with no fringe patterns. (b) \& (c) InSAR post-earthquake from ascending and descending orbits (11 Nov. \& 17 Nov.) and (7 Nov. and 19 Nov.) respectively, (d) the fringe color can indicate to the direction of subsidence or uplift, (e) area of high-stress where fringes very closed to each other. LOS represents the line of sight direction, and $\mathrm{AZ}$ represents the azimuth direction 
using incidence angles clearly affect the capability to measure the vertical component of the displacement (Bon et al., 2017). Large vertical displacement $(\sim 121 \mathrm{~cm}$ uplift $\& \sim 29 \mathrm{~cm}$ subsidence, and $\sim 75 \mathrm{~cm}$ uplift \& $\sim 59 \mathrm{~cm}$ subsidence for ascending and descending data respectively) and horizontal displacement $(\sim 87 \mathrm{~cm} \& \sim 21 \mathrm{~cm}$, and $\sim 53 \mathrm{~cm} \& \sim 40 \mathrm{~cm}$ for ascending and descending data respectively) has been detected, shown in Fig. 7. The interferograms have proven no proof for a prime rupture of the surface. The difference in the total area of deformation and displacement between descending and ascending orbits is due to the difference in the line of sight, the difference in incidence angle and near or far off the area from the satellites (Fig. 8) Next to derive the displacement from the unwrapped phase, it needed to reference displacement map to zero displacement reference point manually. A reference point assumed to be stable was required to transform the relative displacement to absolute displacement.

Here, can subtract the values of reference point from displacement raster, this value is taken from a pixel value with no expected change and high coherence in the same resulted displacement map (this usually requiring prior knowledge of the study area). Finding, the values of the reference points of displacement in ascending and descending data about only 2$4 \mathrm{~mm}$, so the final result of the vertical and horizontal displacement can probably be $\mp 4 \mathrm{~mm}$. The interferogram for the region through the period pre-earthquake (Oct. 30 to Nov 11) no seismic activity evidence. While the interferogram through the period pre and post-earthquake for ascending and descending data (Nov. 7-19), there are more than 33 earthquakes took place with moderate magnitude Mw4.4, in addition to the main Nov. 12 earthquake.

\section{Fault Detection}

understanding of the tectonic setting, direction of geological structures, main transporting direction with InSAR results helps in detection the main faults and reactive faults caused by earthquakes (H. Wanga et al., 2017). Most of the seismic activation in the study area or over the eastern border of Iraq results either from the movement of the Arabian plate and its subduction beneath the Eurasian plate, the Arabian plate moves to the $\mathrm{N}$ and $\mathrm{NE}$ towards the Eurasia plate at an average of about $25 \mathrm{~mm}$ per year (DeMets et al., 2010), or from the tectonic activity of the faults, which may be at the end most of its reactivity are due to the collision movement which result in several main regionals faults in the region such as Main Zagros Fault MZF, Zagros Mountain Front Fault ZMF, High Zagros Fault HZF and dozens of other important and fundamental faults. So, the region is one of the most orogens seismic activity in the world (Barnhart et al., 2018) and now under the influence of an oblique plate convergence pattern (Rahimzadeh et al., 2019) due to tectonic pressures with the north- 
northeast and south-southwest trend, for that most of the faults and other geological structures such as a folds have the direction northwest-southeast, this lead to increase tension of the accumulation of energy in the area and consequently occurrence of the earthquakes. Mostly these earthquakes (include Nov. 12 event) are rather shallow events with a magnitude of less than 6 that have a short return period. Rarely, the earthquake's depth in the Zagros area exceeds 30 kilometers (Trong \& Etwork, 2017).

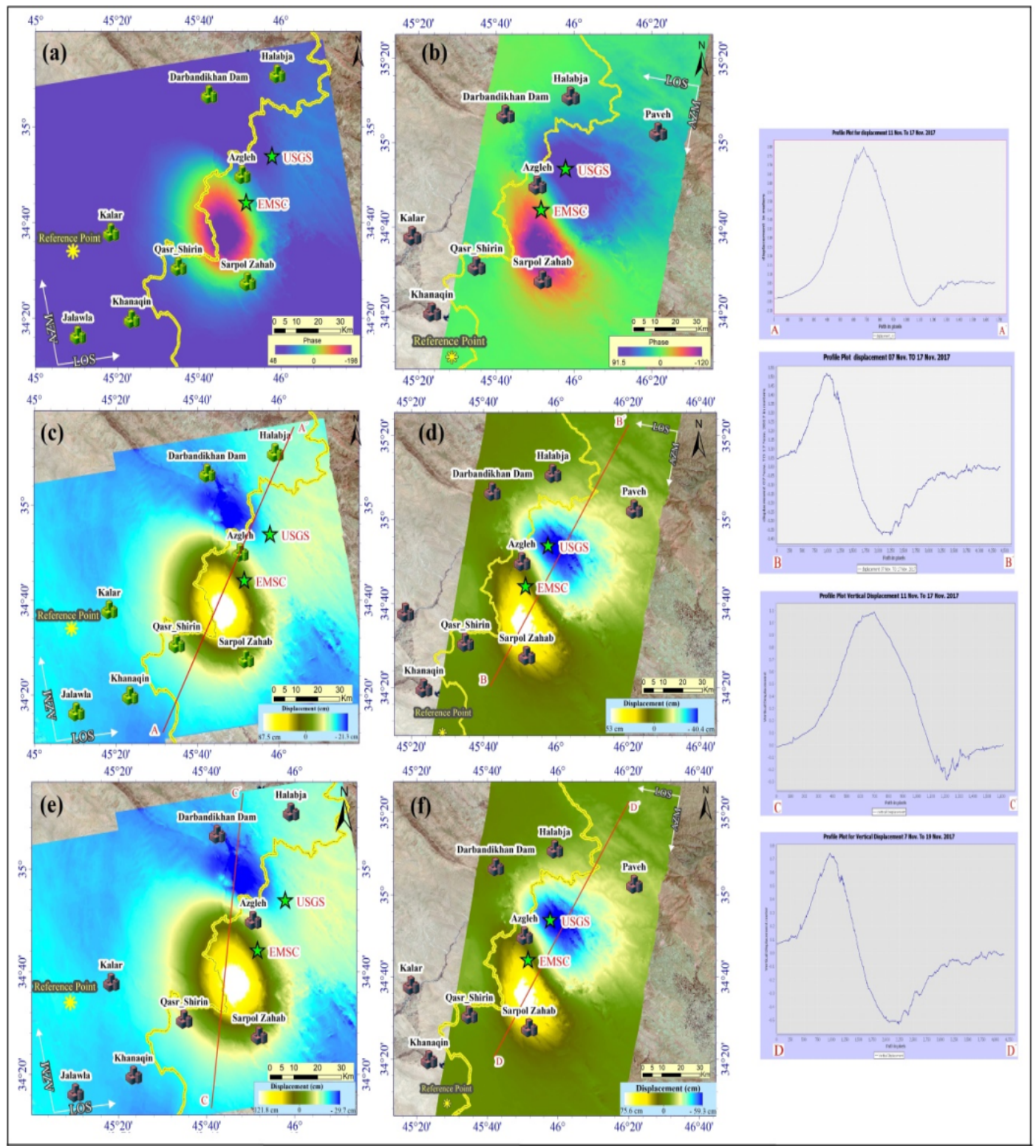

Fig. 7. Representation the final geocoded data of unwrapped interferogram, (a) \& (b) The unwrapped phase of ascending data (Nov.11-17 Nov. 2017) and descending data (Nov. 7-19 Nov. 2017) respectively, (c) and (d) the horizontal displacement by the ascending and descending data respectively, (e) and (f) vertical displacement by the ascending and descending data respectively. Here, negative values imply subsidence, positive stand for uplift. Line of sight (LOS) and the reference points are also reported. Cross sections A-A', B-B', C-C' and D-D' shows profiles through horizontal and vertical displacement for ascending and descending data respectively. 


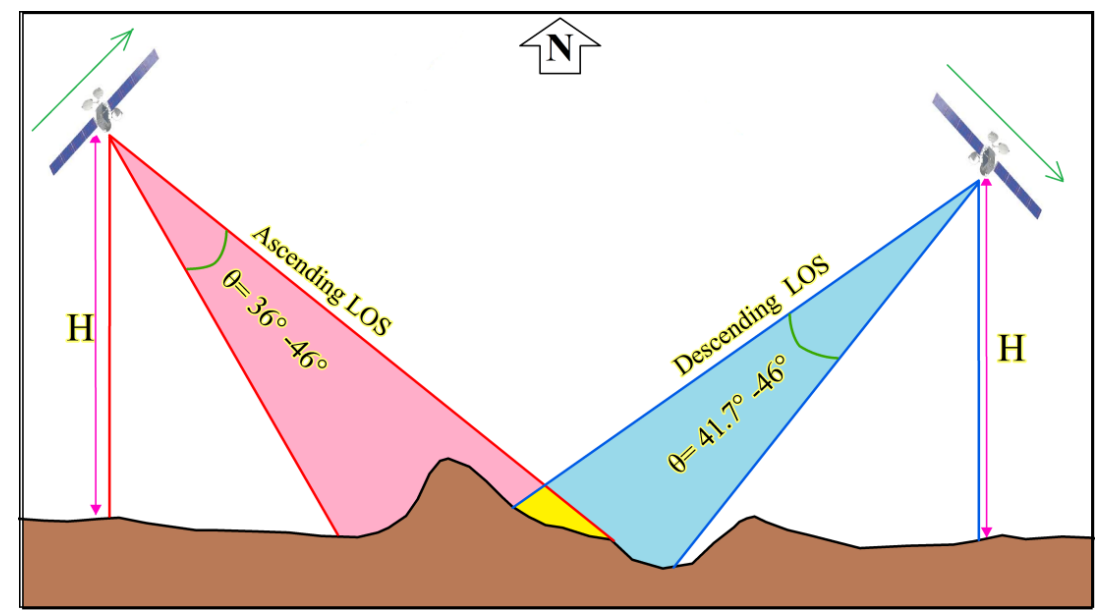

Fig. 8. Difference in the total area of deformation and displacement between descending and ascending orbits is due to the difference in the line of sight, the difference in the azimuth direction, the difference in incidence angle and near or far off the area from the satellites as. In our case study, ascending Incidence angle large than descending Incidence angle, therefore, will cover more area of interest. Ascending LOS close to the uplift area while descending LOS close to the subsidence area, results in the displacement in ascending orbit large then descending orbit.

According to earthquakes archive for period 1967- 2019, the mean earthquake's magnitude about $\mathrm{M}_{\mathrm{w}} 4.47$ with means depth about $16 \mathrm{~km}$, but rupturing of the surface by earthquakes are rare (Walker et al., 2005), this point to most these earthquakes occur in the basement surface which has a depth about 10-14km (Jasim \& Goff, 2006). The relatively intense seismic activity in the region makes the strongest evidence of continuous the basement deformation and most of these deformations with its major earthquakes seem to occur along the Mountain Front Fault.

Preliminary solutions of focal mechanism for the earthquake reported by various agencies (Global Centroid Moment Tensor GCMT; USGS) and (Zare et al., 2017) suggest the rupture takes place either on a thrust fault at mid-crustal depth $(\sim 19 \mathrm{~km})$ that dipping shallowly to the east-northeast, or on a fault dipping steeply to southwest movement along of slip on a fault that has ruptured in an earthquake. According to aftershocks distribution, shown in Figure (9d), uplift and subsidence direction, fault position detection (Fig. 9). The earthquake's depth, and the general faults geometric context, the blind backthrust fault, one never reaches the ground surface; the southwest-dipping solution was interpretation. The interferograms maps supply no evidence of a preliminary surface rupture of the main earthquake fault, indicate that the earthquake was placed on a blind fault. Basically, while earthquakes that are caused by thrust faults generate a stronger earthshaking compared to the 
earthquakes occurred as the result of the normal or strike-slip faults (Trong \& Etwork, 2017), this can help to interpreted the earthquake placed on a thrust fault.

The Nov. 12 earthquake depth can give us other explanations to support our conclusions that the earthquake dipping steeply to the southwest. Most of the seismic researches and studies show that the depth of this earthquake is between 15-25 km (Feng et al., 2018; Utkucu, 2017; Zare et al., 2017), which indicates that the earthquake occurred within the basement (Barnhart et al., 2018). This deformation type is known as thick-skinned deformation, which associated with thrust faults steepen dipping at depth (Coward \& Potts, 1983). Whereas thin-skinned indicate to the deformation that doesn't involve the basement, which associated with gently dipping thrust faults and ramp-flat trajectories (Butler, 1982).

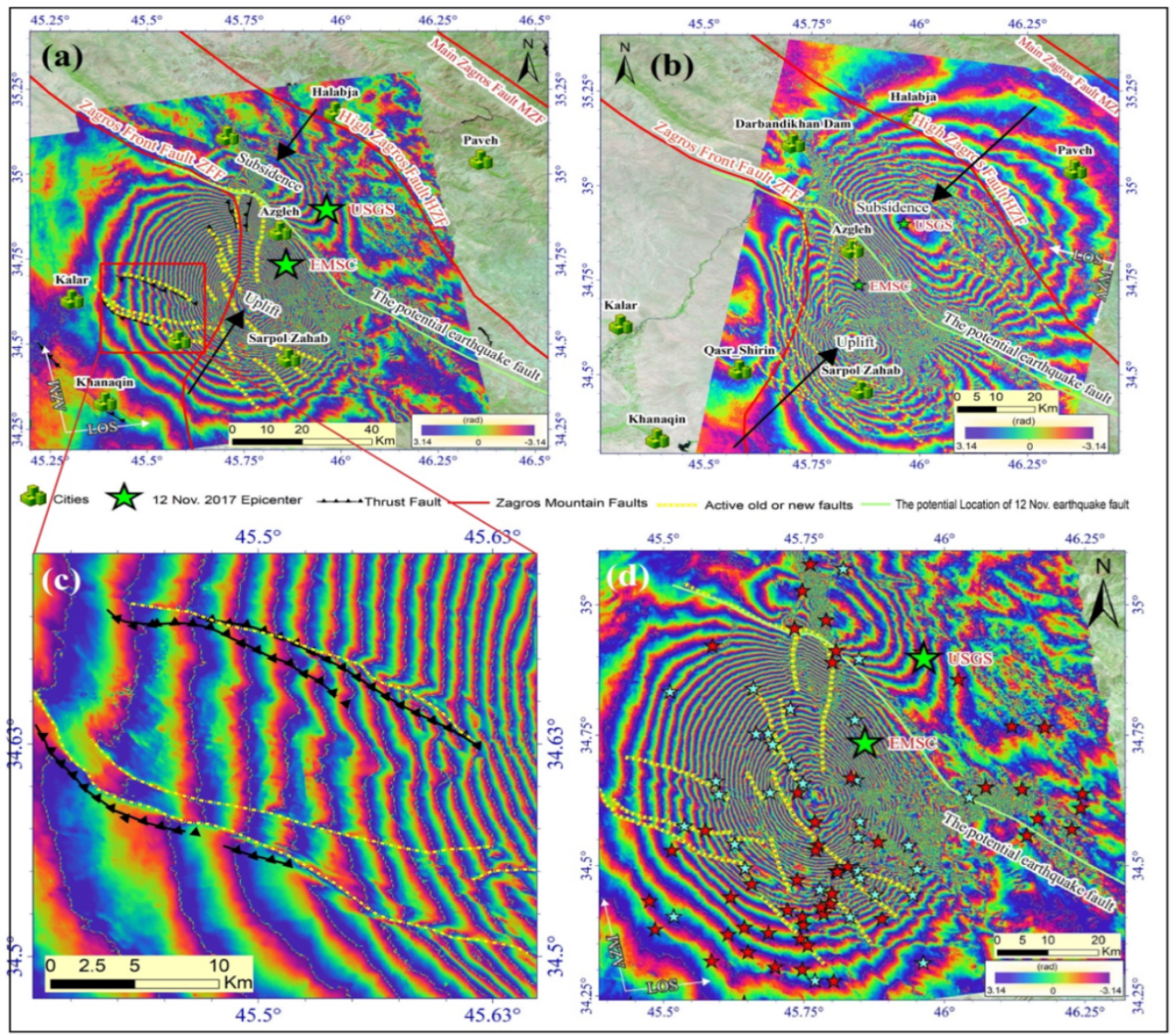

Fig. 9. The geocoded data of phase interferogram. (a) \& (b) The phase of ascending data (Nov. 11-17, 2017) and descending data (Nov. 7-19, 2017) respectively, (c) The faults from geological map coincide with the result derived from the interferometric phase maps. (d) Aftershocks earthquakes epicenter distribution during period Nov. 12-26, 2017, the red star denotes the epicenter location (USGS) while cyan star denote the epicenter location (EMSC). Red lines indicate the proposed locations of major regionals faults from (Barnhart et al., 2018; Berberian, 1995); MZF: Main Zagros Fault; HZF: High Zagros Fault; MFF: Mountain Front Fault. 


\section{CONCLUSIONS}

The analysis fringe patterns on interferometric maps (Fig. 9a and 9b) yellow line, numerous areas of phase discontinuities indicate new minor faults ruptured on the surface, in addition to displacement on old faults or fracture was detected. Many faults derived from the geological map coincide with the result from the interferometric phase maps, (Fig. 9c). The recently activity faults or fractures appear to be related to Nov. 12, earthquake. Aftershock earthquake epicenter distribution during period Nov. 12- 26, 2017 (USGS and EMSC) in Fig. $9 \mathrm{~d}$, most of these epicenters (about $65 \%$ ) located on or near these detected faults or ruptures.

Generally, the earthquake arises from the fault break or fault displacement result in the earthquake. The Nov. 12 earthquake caused by blind oblique-thrust fault and did not break the surface (K. Chen, et al., 2018) but the location of the main fault associated with this earthquake can be first predicted by analyzing InSAR results such as phase and displacement maps, the location and direction of the uplifting and subsiding and its volume (area) with the high stress -area. The potential Nov. 12 earthquake fault detected and draws on the phase map of ascending and descending data (Figs .9a and 9b) light green line, depends on many factors: i) Area of high stress, which represents at the area with very closed fringes, especially closed to a fault, this point discussed in Fig. 6 e. ii. Area and direction of uplift and subsidence. Based on thrust fault geometry, the displacement takes place along the fault plane where the hanging-wall move up (uplift) relative to footwall that moved down (subsidence) with large displacement indicated always to hanging-wall. In case the Nov. 12 earthquake in (Figs. 6 and 7a\&b), the large displacement (uplift) with a large volume (area) took place in SW (hanging-wall) while less displacement and volume occur in NE (footwall). Therefore, the line separates them indicates potential earthquake fault.

Finally, there may be no way to predict occurrence of the earthquakes, but the remote sensing techniques, especially radar imaging techniques, in addition to a lot of fieldwork, seismic and gravity studies to determine the locations of major faults and extensions accurately; provide an advanced way to determine the expected areas of the earthquake take place, its effects and thus take precautions to protect people and their property

\section{REFERENCES}

Abdulnaby, W., Al-Mohmed, R., and Mahdi, M., 2016. Seismicity and recent stress regime of Diyala City, IraqIran border. Modeling Earth Systems and Environment, 2(3): 142.

Abdulnaby, W., Mahdi, H., Al-Shukri, H., and Numan, N., 2014. Stress patterns in Northern Iraq and surrounding regions from formal stress inversion of earthquake focal mechanism solutions. Pure and Applied Geophysics, 171(9): 2137-2153.

Abdulnaby, W., Mahdi, H., Numan, N., and Al-Shukri, H., 2014. Seismotectonics of the Bitlis-Zagros fold and thrust belt in northern Iraq and surrounding regions from moment tensor analysis. Pure and Applied Geophysics, 171(7): 1237-1250.

Adams, R. D., and Barazangi, M., 1984. Seismotectonics and seismology in the Arab region: a brief summary 
and future plans. Bulletin of the Seismological Society of America, 74(3):1011-1030.

Agency, E. S., 2013. Sentinel-1 User Handbook.

Al-Amri, A., Arthur, R., and Tariq, A. K., 2008. Improving the level of seismic hazard parameters in Saudi Arabia using earthquake location. Arabian Journal of Geosciences, 1(1): 1-15.

Al-Azzawi, N. K., and Hamdoon, A. N., 2008. Structure and geomorphology of Shaikhan Anticline-Northern Iraq. Iraqi National Journal of Earth Sciences, 8(1): 54-63.

Al-Jiboury, T. H., 1991. Hydrology and Geomorphology of Diyala river. Ph. D. Thesis, Univesity of Baghdad, Baghdad, Iraq.

Al-Sudani, H. I. Z., 2018. Study of Morphometric Properties and Water Balance Using Thornthwaite Method in Khanaqin Basin, East of Iraq. Journal of University of Babylon, 26(3): 165-175.

Alridha, N. A., and Mohammed, H. J., 2015. Seismicity study of Khanaqin Area. Iraqi Journal of Science, 56(1A): $181-190$.

Alsinawi, S. A., 2002. Seismicity, seismotectonics, crustal structure and attenuation data on Iraq. In RELEMR Meetings, Antakya, Turkey.

Alsinawi, S., and Ghalib, H. A. A., 1975. Historical seismicity of Iraq. Bulletin of the Seismological Society of America, 65(2): 541-547.

Barnhart, W. D., Brengman, C. M. J., Li, S., and Peterson, K. E., 2018. Ramp-flat basement structures of the Zagros Mountains inferred from co-seismic slip and afterslip of the $2017 \mathrm{M} \mathrm{w} 7$. 3 Darbandikhan, Iran / Iraq earthquake. Earth and Planetary Science Letters, 496: 96-107. https://doi.org/10.1016/j.epsl.2018.05.036

Berberian, M., 1995. Master "blind" thrust faults hidden under the Zagros folds: active basement tectonics and surface morphotectonics. Tectonophysics, (241): 193-224. Retrieved from https://doi.org/10.1016/00401951(94)00185-C

Bon, R., Meisina, C., Cigna, F., Herrera, G., Notti, D., Bricker, S., and Ezquerro, P., 2017. Exploitation of satellite A-DInSAR time series for detection, characterization and modelling of land subsidence. https://doi.org/10.3390/geosciences7020025

Butler, R. W. H., 1982. The terminology of structures in thrust belts. Journal of Structural Geology, 4(3): 239245.

Chelbi, S., Khireddine, A., and Charles, J. P., 2011. Interferometry process for satellite images SAR. In 2011 7th International Conference on Electrical and Electronics Engineering (ELECO) (pp. II-200). IEEE.

Chen, C. W., 2001. Statistical-cost network-flow approaches to two-dimensional phase unwrapping for radar interferometry.

Chen, K., Chen, K., Xu, W., Mai, P. M., Gao, H., Zhang, L., and Ding, X., 2018. The 2017 Mw 7 . 3 Sarpol Zah $\bar{a} \mathrm{~b}$ Earthquake, Iran: A compact blind shallow- dipping thrust event in the mountain front fault basement Tectonophysics The 2017 Mw 7 . 3 Sarpol Zahāb Earthquake, Iran: A compact blind shallow- dipping thrust event in the . Tectonophysics, 747-748(October), 108-114. https://doi.org/10.1016/j.tecto.2018.09.015

Chen, K., Xu, W., Mai, P. M., Gao, H., Zhang, L., and Ding, X., 2018. The 2017 Mw 7.3 Sarpol Zahāb Earthquake, Iran: A compact blind shallow-dipping thrust event in the mountain front fault basement. Tectonophysics, 747: 108-114.

Colesanti, C., and Wasowski, J., 2006. Investigating landslides with space-borne Synthetic Aperture Radar (SAR) interferometry. Engineering Geology, 88(3-4): 173-199.

Costantini, M., 1996. A phase unwrapping method based on network programming [A]. In: ESA Eds. Proceedings of the "Fringe '96" Workshop, ESA SP-406 [C]. Zurich, Switzerland, 261 272.

Coward, M. P., and Potts, G. J., 1983. Complex strain patterns developed at the frontal and lateral tips to shear zones and thrust zones. Journal of Structural Geology, 5(3-4): 383-399.

Curlander, J. C., and McDonough, R. N., 1991. Synthetic aperture radar- Systems and signal processing(Book). New York: John Wiley \& Sons, Inc, 1991.

DeMets, C., Gordon, R. G., and Argus, D. F., 2010. Geologically current plate motions. Geophysical Journal International, 181(1):1-80.

Elliott, J. R., Jolivet, R., González, P. J., Avouac, J.-P., Hollingsworth, J., Searle, M. P., and Stevens, V. L. 2016. Himalayan megathrust geometry and relation to topography revealed by the Gorkha earthquake. Nature Geoscience, 9(2): 174.

European Space Agency. 2019. SNAP - ESA Sentinel Application Platform v.7. Retrieved from http://step.esa.int/

Farr, T. G., Rosen, P. A., Caro, E., Crippen, R., Duren, R., Hensley, S., ... Roth, L. 2007. The shuttle radar topography mission. Reviews of Geophysics, 45(2).

Feng, W., Samsonov, S., Almeida, R., Yassaghi, A., Li, J., Qiu, Q., ... Zheng, W., 2018. Geodetic Constraints of the 2017 Mw7. 3 Sarpol Zahab, Iran Earthquake, and Its Implications on the Structure and Mechanics of the Northwest Zagros Thrust-Fold Belt. Geophysical Research Letters, 45(14): 6853-6861.

Ferretti, A., Monti-Guarnieri, A., Prati, C., Rocca, F., and Massonet, D., 2007. InSAR Principles-Guidelines for SAR Interferometry Processing and Interpretation, TM-19. The Netherlands: ESA Publications. 
FerrettiA, M., and GuarnieriA, P., 2007. InSAR Principles: GuidelinesforSARInterferometryPro cessingandInterpretation. AGNoordwijk: ESAPublications.

Fouad, S. F. A. , 2015. Tectonic map of Iraq, scale 1: 1000 000, 2012. Iraqi Bulletin of Geology and Mining, 11(1): $1-7$.

Ghalib, H. A., and Alsinawi, S. A., 1974. Seismotectonics of the Arabian Peninsula-A Global Tectonic Approach. Bull. Coll. Sci, 15: 151-169.

Goldstein, R. M., and Werner, C. L., 1998. Radar interferogram filtering for geophysical applications. Geophysical Research Letters, 25(21): 4035-4038.

H. Wanga, J. Liu-Zeng, J., and Feng, Z. S., 2017. Sentinel-1 observations of the 2016 Menyuan earthquake: A buried reverse event linked to the left-lateral Haiyuan fault, 61(October 2016), 14-21. https://doi.org/10.1016/j.jag.2017.04.011

Hanssen, R., 1998. Assessment of the role of atmospheric heterogeneities in ERS tandem SAR interferometry. Delft Univ., Delft, The Netherlands, DEOS Rep, 12(698.1).

Hu, J., Li, Z., Zhu, J., Ren, X., and Ding, X., 2010. Inferring three-dimensional surface displacement field by combining SAR interferometric phase and amplitude information of ascending and descending orbits. Science China Earth Sciences, 53(4): 550-560.

Huang, Y., Xu, H., Chen, J., Li, C., Li, J., and Zhou, Y., 2000. An algorithm for interferometric SAR data processing. Journal of Electronics (China), 17(3): 202-207.

Jasim, S., and Goff, J., 2006. Geology of Iraq, Published by Dolin, Prague \& Moravian Museum Brno. Zech. Repub.

Jouanne, F., Awan, A., Madji, A., Pêcher, A., Latif, M., Kausar, A., ... Khan, N. A., 2011. Postseismic deformation in Pakistan after the 8 October 2005 earthquake: Evidence of afterslip along a flat north of the Balakot-Bagh thrust. Journal of Geophysical Research: Solid Earth, 116(B7).

List, M., 2018. How to create a DEM from Sentinel-1 Data, (March), 1-15.

List, M., and Image, S., 2018. Generate Inundation Map using Sentinel-1 GRD with S1TBX In this document you will find : A ) System Requirements B ) Background, (November), 1-14.

Lu, Z., and Dzurisin, D., 2014. InSAR imaging of Aleutian volcanoes. In InSAR Imaging of Aleutian Volcanoes (pp. 87-345). Springer.

Miranda, N., 2014. Definition of the TOPS SLC deramping function for products generated by the S-1 IPF. Eur. Space Agency, Paris, France, Tech. Rep.

Moreira, A., 1991. Improved multilook techniques applied to SAR and SCANSAR imagery. IEEE Transactions on Geoscience and Remote Sensing, 29(4): 529-534.

Mousavi, Z., 2010. Interseismic deformation of two major active faults in eastern Iran : contribution of satellite radar interferometry ( InSAR ). Supervision, (June).

Nishimura, T., Tobita, M., Yarai, H., Ozawa, S., Murakami, M., Yutsudo, T., ... Kawamoto, S., 2008. Crustal deformation and a preliminary fault model of the 2007 Chuetsu-oki earthquake observed by GPS, InSAR, and leveling. Earth, Planets and Space, 60(11): 1093-1098.

Olmsted, C., 1993. Scientific SAR User's Guide.

Oveisgharan, S., and Zebker, H. A., 2006. Estimating snow accumulation from InSAR correlation observations. IEEE Transactions on Geoscience and Remote Sensing, 45(1): 10-20.

Prats-Iraola, P., Scheiber, R., Marotti, L., Wollstadt, S., and Reigber, A., 2012. TOPS interferometry with TerraSAR-X. IEEE Transactions on Geoscience and Remote Sensing, 50(8): 3179-3188.

Pritchard, M. E., 2006. InSAR, a tool for measuring Earth's surface deformation. Physics Today, 59(7): 68.

Qu, F., Lu, Z., Kim, J.-W., and Zheng, W., 2019. Identify and monitor growth faulting using InSAR over Northern Greater Houston, Texas, USA. Remote Sensing, 11(12),:1498.

Qu, F., Lu, Z., Zhang, Q., Bawden, G. W., Kim, J.-W., Zhao, C., and Qu, W., 2015. Mapping ground deformation over Houston-Galveston, Texas using multi-temporal InSAR. Remote Sensing of Environment, 169: 290-306.

Rahimzadeh, B., Bahrami, S., Mohajjel, M., and Mahmoudi, H., 2019. Active strike-slip faulting in the Zagros Mountains : Geological and geomorphological evidence of the pull-apart Zaribar Lake basin, Zagros, NW Iran Journal of Asian Earth Sciences Active strike-slip faulting in the Zagros Mountains : Geological and geo. Journal of Asian Earth Sciences, (January), 0-1. https://doi.org/10.1016/j.jseaes.2018.12.017

Sadeghi, S., and Yassaghi, A., 2016. Spatial evolution of Zagros collision zone in Kurdistan, NW Iran: Constraints on Arabia-Eurasia oblique convergence. Solid Earth, 7(2): 659-672.

Sakar, N., Brcic, R., Gonzalez, F. R., and Yague-Martinez, N. (2015). An advanced co-registration method for TOPSAR interferometry. In 2015 IEEE International Geoscience and Remote Sensing Symposium (IGARSS) (pp. 5240-5243). IEEE.

Sansosti, E., Berardino, P., Manunta, M., Serafino, F., and Fornaro, G., 2006. Geometrical SAR image registration. IEEE Transactions on Geoscience and Remote Sensing, 44(10): 2861-2870.

Sentinels, P. O. D., 2013. Team: Sentinels POD Service File Format Specifications. European Space Agency, Paris, France.

Shirzaei, M., Bürgmann, R., and Fielding, E. J., 2017. Applicability of Sentinel-1 terrain observation by 
progressive scans multitemporal interferometry for monitoring slow ground motions in the San Francisco Bay Area. Geophysical Research Letters, 44(6): 2733-2742.

Trong, I. R. A. N. S., and Etwork, M. O. N. (2017). Report of the november 12, 2017 sarpol-e zahab.

Utkucu, M., 2017. Preliminary Seismological Report on the November 12, 2017 Northern Iraq/Western Iran Earthquake. Sakarya University Https://Doi. Org/10.13140/RG, 2(17781.27364).

Veci, L., 2015. Interferometry Tutorial. Array Systems. Available Online: Http://Sentinel1. S3. Amazonaws. Com/Docs/S1TBX\% 20Stripmap\% 20Interferometry\% 20with\% 20Sentinel-1\% 20Tutorial. Pdf (Accessed on 12 August 2017).

Vilardo, G., Ventura, G., Terranova, C., Matano, F., and Nardò, S., 2009. Ground deformation due to tectonic, hydrothermal, gravity, hydrogeological, and anthropic processes in the Campania Region (Southern Italy) from Permanent Scatterers Synthetic Aperture Radar Interferometry. Remote Sensing of Environment, 113(1): 197-212.

Walker, R. T., Andalibi, M. J., Gheitanchi, M. R., Jackson, J. A., Karegar, S., and Priestley, K., 2005. Seismological and field observations from the 1990 November 6 Furg (Hormozgan) earthquake: a rare case of surface rupture in the Zagros mountains of Iran. Geophysical Journal International, 163(2): 567579.

Www.iris.edu/earthquake. 2017. Magnitude 7.3 IRAQ Sunday, November 12, 2017 at 18:18:17 UTC.

Xia, Y., 2005. Bam earthquake: Surface deformation measurement using radar interferometry. Acta Seismologica Sinica, 18(4): 451-459.

Zare, M., Kamranzad, F., Parcharidis, I., and Tsironi, V., 2017. Preliminary report of Mw7. 3 Sarpol-e Zahab, Iran earthquake on November 12, 2017. EMSC Report, 1-10.

Zebker, H. A., and Lu, Y., 1998. Phase unwrapping algorithms for radar interferometry: residue-cut, leastsquares, and synthesis algorithms. JOSA A, 15(3): 586-598.

Zhang, Y. F., Wang, X. P., Pan, Y. X., and Hu, R., 2012. Diurnal relationship between the surface albedo and surface temperature in revegetated desert ecosystems, Northwestern China. Arid Land Research and Management, 26(1): 32-43. 